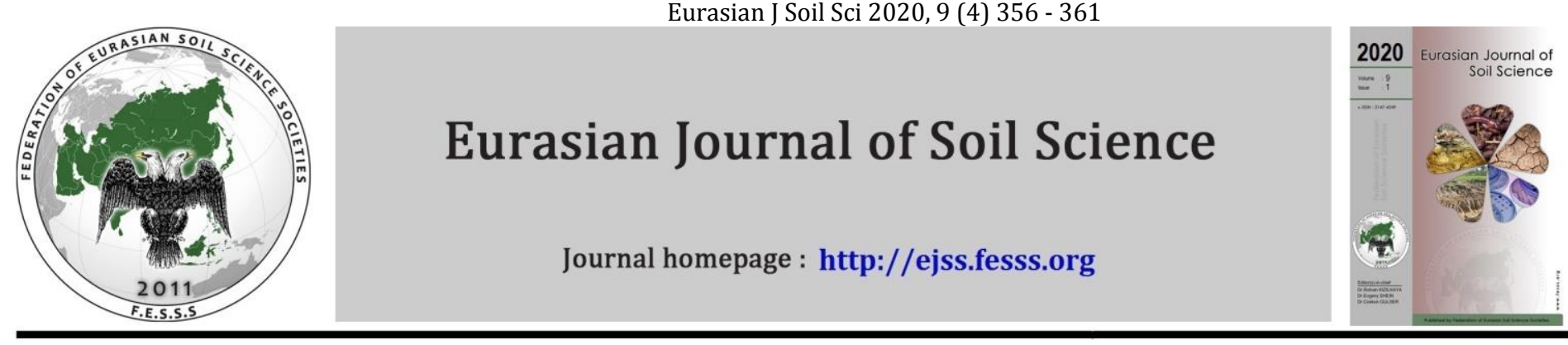

\title{
Mechanisms of copper immobilization in Fluvisol after the carbon sorbent applying
}

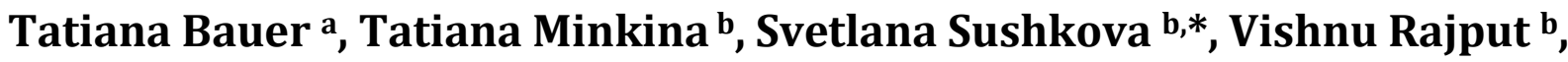 \\ Andrei Tereshenko b, Aleksandr Nazarenko a, Saglara Mandzhieva b, Andrey Sushkov b \\ a Federal Research Center the Southern Scientific Center of the Russian Academy of Sciences, Rostov-on-Don, Russia \\ b Southern Federal University, Rostov-on-Don, Russia
}

\section{Article Info}

Received : 17.09 .2019

Accepted : 19.08.2020

\begin{abstract}
Biochar is widely used sorbent for soil remediation but the mechanism of its effect on immobilization of metals and particular processes of metal transformation are still unclear. We designed an incubation experiment to investigate the impact of wood biochar to copper $(\mathrm{Cu})$ contamination in Calcaric Fluvisols Loamic. The efficiency of biochar implementation for reduction of $\mathrm{Cu}$ mobility in soil has been studied using combined method of heavy metal fractioning (Minkina et al., 2013). It was shown that the use of sorbent into polluted soil results in the change of fraction-group composition of metal compounds, fixation of $\mathrm{Cu}$ due to reduction of weakly bound forms and increase of the part of residual and metal fractions strongly bound with organic matter. Decrease of pollutant mobility occurs along an increase of the dose of a sorbent. The greater effect was observed after use of biochar in the concentration $2.5 \%$. Thus, the present study demonstrates the possible remediation of soil contaminated by heavy metals using biochar and provides a particular strategy for remediation of soils contaminated with $\mathrm{Cu}$.
\end{abstract}

Keywords: Biochar, calcaric fluvisols loamic, loosely bound compounds, copper, remediation.

(C) 2020 Federation of Eurasian Soil Science Societies. All rights reserved

\section{Introduction}

In present, heavy metal (HM) pollution brings the serious threat to the environment. Metals are not biodegradable over time and accumulate in environmental objects posing a threat to various links of the trophic chains (Kabata-Pendias, 2011). HM pollution results to deterioration of soil quality and loss of soil functions (Schloter et al., 2017; Wang et al., 2017) that brings a danger to human health (Wood et al., 2016; Shen et al., 2017). Therefore, the soil remediation polluted with HM became the most studied and global problem (Zota et al., 2009; Violante et al., 2010; Ju et al., 2019).

Recently, various methods of soil cleaning from HMs and preventing their migration into adjacent environments have been developed and tested. In particular, carbon sorbents (for example, activated carbon and biochar), which include the products of thermal treatment of materials of plant and animal origin as well as some industrial wastes are widely used for the immobilization of HMs in soil (Kars and Dengiz, 2020; Burachevskaya et al., 2020). Due to the large specific surface area and high porosity, their introduction into

\footnotetext{
Tatiana Bauer

Tatiana Minkina

* Svetlana Sushkova

Vishnu Rajput

Andrei Tereshenko

Aleksandr Nazarenko

Saglara Mandzhieva

Andrey Sushkov
}
: bauertatyana@mail.ru
: tminkina@mail.ru
: snsushkova@sfedu.ru
: rajput.vishnu@gmail.com
: tereshch1@gmail.com
: nazarav@ssc-ras.ru
䱛 : msaglara@mail.ru
증 : sushkovandrey1@gmail.com

0000-0002-6751-8686

0000-0003-3022-0883

0000-0003-3470-9627

0000-0002-6802-4805

0000-0001-5102-6743

0000-0001-9684-693X

0000-0001-6000-2209

0000-0001-9789-3615 
soil reduces the bioavailability of pollutants (Houben et al., 2013; Ahmad et al., 2018), toxicity, and accumulation in living organisms (Wang et al., 2020). The use of biochar is becoming more popular since it has sorption properties similar to activated carbon, but is much cheaper (Ahmad et al., 2014; Huggins et al., 2016). Biochar is a solid high-carbon material obtained by thermal decomposition of biomass in conditions of complete or partial absence of oxygen (Cao and Harris, 2010). Use of biochar provides with some advantages such as available sources of raw materials, low cost, environmental safety, and the possibility of large-scale implementation. Biochar is recognized as a "green" cost-effective ameliorant for recovery of the environment (Rees et al., 2014), stabilization of HM in soils and reduction of their accumulation by the plants (Lomaglio et al., 2017; Poucke et al., 2018). In addition to immobilization of pollutants, the use of biochar has a positive effect on the chemical properties of soil such as changes of $\mathrm{pH}$, cation exchange capacity, and the content of nutrients (Warnock et al., 2007) that provides the important advantages for this remediation method (Laird et al., 2010).

The purpose of the study is to analyze the efficiency of biochar for copper immobilization in contaminated soil using a combined fractionation scheme.

\section{Material and Methods}

The studies were carried out as a model experiment on Calcaric Fluvisol (Loamic) (at the depth 0-20 $\mathrm{cm}$ ) collected in the Severnyi Donets River floodplain (Kamensk-Shakhtinskii district, Rostov oblast, Russia). The analyzed soil is characterized by following physical and chemical properties: $\mathrm{C}_{\mathrm{org}}-4.3 \%$; $\mathrm{pH}$ 7.5; exchangeable cations $\left(\mathrm{Ca}^{2+}+\mathrm{Mg}^{2+}\right)-38.1 \mathrm{cM}(+) / \mathrm{kg} ; \mathrm{CaCO}_{3}-0.6 \%$; content of physical clay $-55.8 \%$, silt $32.0 \%, \mathrm{Cu}-43.7 \mathrm{mg} / \mathrm{kg}$. Soil was added with carbon sorbent in a dose 2.5 mass $\%$ per $20-\mathrm{cm}$ arable soil layer that corresponds to approximately $500 \mathrm{~kg} / 100 \mathrm{~m}^{2}$ or $50 \mathrm{t} / \mathrm{ha}$.

Cooper (Cu) in a dose of 10 APC $(1320 \mathrm{mg} / \mathrm{kg}$ ) (GN 2.1.7.2511-09, 2009) per the pure element was used as a pollutant. Before the experiment, soil samples were dried, grinded to the particles $<1 \mathrm{~mm}$, plant roots and large inclusions were removed. 1000 -g samples of soil were placed into the $2 \mathrm{~L}$ vessels, supplied with dry $\mathrm{Cu}$ oxide, and thoroughly mixed with a glass rod. After 6 months of incubation of soil with metal, biochar was introduced into the vessels in the doses $1 \%$ and $2.5 \%$ at the depth $20 \mathrm{~cm}$, corresponding to approximately $200 \mathrm{~kg} / 100 \mathrm{~m}^{2}$ and $500 \mathrm{~kg} / 100 \mathrm{~m}^{2}$ or $20 \mathrm{t} / \mathrm{ha}$ and $50 \mathrm{t} / \mathrm{ha}$. In a month after addition of the sorbent, the dry soil was grinded and sifted through a sieve with a $1 \mathrm{~mm}$ hole for further analyzes. Experiment was carried out in three replications tat natural illumination. Optimal moisture in the vessels was maintained at $60 \%$ of total water capacity over whole experiment period.

Biochar for the experiment was produced by pyrolysis of birch wood on retort equipment according to GOST 7657-84 (GOST 7657-84, 1976) grade A, class 1 (pyrolysis temperature $550^{\circ} \mathrm{C}$, biochar fractions $3-5 \mathrm{~mm}$ ). Measurements of the specific surface area and porosity were carried out on a volumetric analyzer ASAP 2020 by the low-temperature nitrogen adsorption. Biochar characterized with following parameters: specific surface area $-540 \mathrm{~m}^{2} / \mathrm{g}$, total volume of pores $-0.81 \mathrm{~cm}^{3} / \mathrm{g}$; volume of micropores $(<2 \mathrm{~nm})-0.63$ $\mathrm{cm}^{3} / \mathrm{g}$, mesopores $(2-500 \mathrm{~nm})-0.04 \mathrm{~cm}^{3} / \mathrm{g}$, and macropores $(>500 \mathrm{~nm})-0.14 \mathrm{~cm}^{3} / \mathrm{g}$.

The surface area of biochar was also analyzed using laser scanning confocal microscopy (3D- scanning laser microscope (Keyence VK-9700) with a violet laser wavelength of $408 \mathrm{~nm}$, which allows distinguishing of the parts in three planes with a resolution up to 200-300 nm) to design 3D models of microrelief of the biochar sample (Figure 1). Considering that the size of macropores is $500 \mathrm{~nm}$ and more, the values of surface area measured by optical and sorption methods can be compared. The measurement of the surface area was carried out by calculation of the average value of the area of identical sections of the $10 \times 10 \mu \mathrm{m}$ sample (red square), placed randomly within the studied area. The sample was measured in 10 replications. It was found that the biochar sample has a sufficiently large integral surface area $797.439 \pm 81 \mu \mathrm{m}^{2}$.
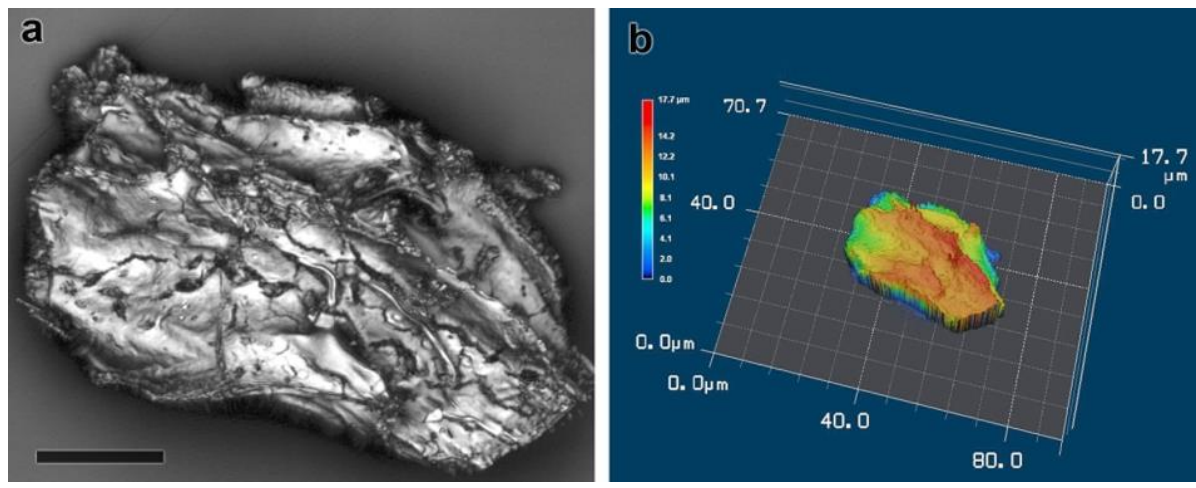

Figure1. Biochar sample and its 3D microrelief model obtained using laser scanning confocal microscopy. Scale: $10 \mu \mathrm{m}$. 


\section{Results Discussion}

The total contents of $\mathrm{C}, \mathrm{H}$ and $\mathrm{N}$ in the carbonaceous sorbents were determined using a CHN elemental analyzer (TOC-L CPN Shimadzu, Japan). Ash content was measured by heating sorbents at $650{ }^{\circ} \mathrm{C}$ for $3 \mathrm{~h}$ and 0 content was calculated by mass difference. Molar ratios of elements, often used to estimate the aromaticity $(\mathrm{H} / \mathrm{C}$ ratio) and polarity $(\mathrm{O} / \mathrm{C},(\mathrm{O}+\mathrm{N}) / \mathrm{C}$ are also provided in Table 1.

Table 1. Elemental composition of biochar

\begin{tabular}{llllllll}
\hline $\mathrm{C}$ & $\mathrm{N}$ & $\mathrm{H}$ & $\mathrm{O}$ & Ash & $\mathrm{H} / \mathrm{C}$ & $\mathrm{O} / \mathrm{C}$ & $(\mathrm{N}+0) / \mathrm{C}$ \\
\hline 74.3 & 2.3 & 2.7 & 12.9 & 7.8 & 0.43 & 0.13 & 0.16 \\
\hline
\end{tabular}

The IR spectra were measured on an FSM-1202 spectrometer in transmission mode using a DTGS detector. The spectra were acquired in the range from 4000 to $400 \mathrm{~cm}^{-1}$ with a resolution of $4 \mathrm{~cm}^{-1}$ and 100 scans. $200 \mathrm{mg} \mathrm{KBr}$ pellet of $13 \mathrm{~mm}$ in diameter was used as a reference sample. Studied samples with mass of 0.06 $\mathrm{mg}$ were ground and milled with $\mathrm{KBr}$ and pressed into pellet of total mass $200 \mathrm{mg}$.

IR spectrum of biochar (Figure 2) demonstrated strong and broad band near at $3100-3600 \mathrm{~cm}^{-1}$ which was attributed to $\mathrm{O}-\mathrm{H}$ stretching vibrations ( $\mathrm{Li}$ and Chen, 2018) from hydroxyl functional groups or adsorbed water. Narrow peaks at 2918 and $2846 \mathrm{~cm}^{-1}$ probably related to asymmetric and symmetric stretching vibrations of aliphatic C-H groups of cellulose, respectively (Lamaming et al., 2015). Bands near 1570 and $1476 \mathrm{~cm}^{-1}$ could be attributed to $\mathrm{C}=\mathrm{C}$ stretching and $\left(\mathrm{sp}^{3}\right) \mathrm{C}-\mathrm{H}$ bending vibrations, respectively. Strong and broad peak at 900-1250 $\mathrm{cm}^{-1}$ was assigned to -C-O-C- symmetric stretching or phenolic functional groups and ethers (Li and Chen, 2018).

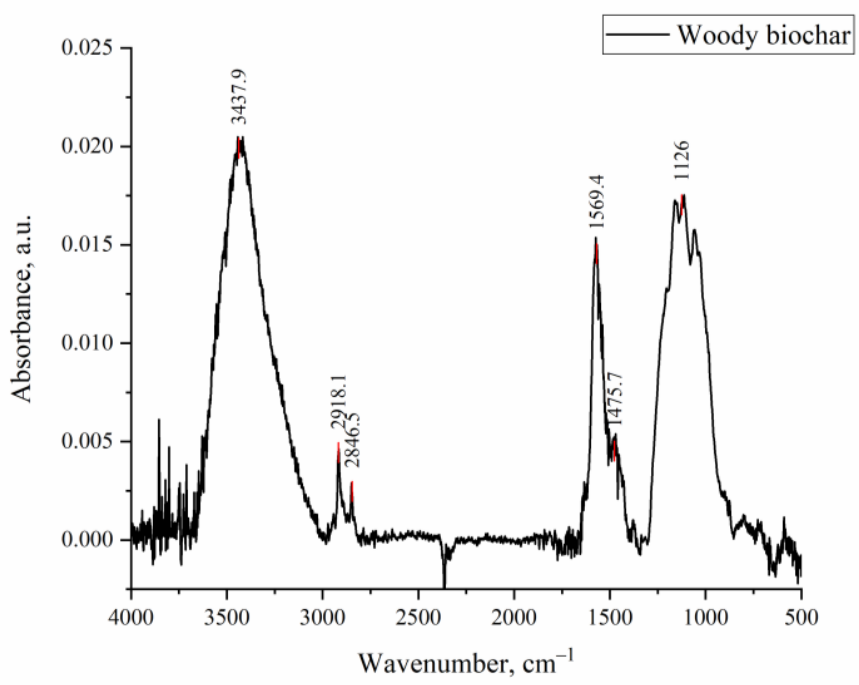

Figure 2. The FTIR spectra of biochar

The study of the mechanisms of $\mathrm{Cu}$ immobilization in Fluvisol after the introduction of a carbonaceous sorbent was carried out using a combined fractionation scheme (Minkina et al., 2013), which makes possible to determine the composition of loosely (LB) and strongly bound (SB) HM-containing compounds in details, comparing other methods and follow the dynamics of the bound strength of metals and main soil components. This scheme is based on a combination of the results obtained by the Tessier method (Tessier et al., 1979) and parallel extractions (Minkina et al., 2018). The content of metal in fractions included in LB and SB groups of compounds was determined by the analytical and computational methods (Figure 3).

The efficiency of biochar for the remediation of contaminated soils was studied using a combined fractionation scheme since the analysis of changes in the fractional-group composition of $\mathrm{Cu}$-containing compounds in the remediation conditions allows a deeper understanding of the mechanism of the sorbent effect on the immobilization of metal, the redistribution of metal compounds, and their transformation processes.

The domination of strongly bound $\mathrm{Cu}$ compounds ( $92 \%$ of total fractions), which is mainly supported by the retention of metal by primary and secondary minerals $(66 \%)$ was observed in uncontaminated meadow soil (control) (Table 2). Mobility of $\mathrm{Cu}$ in soils was low (8\%) and represented mainly by specifically adsorbed metal compounds.

The content of all forms of $\mathrm{Cu}$ increases with artificial soil contamination and their ratio increases (up to $38 \%$ ) in the content of LB compounds (Table 2). The content of complex and specifically adsorbed metal 
compounds adsorbed on $\mathrm{Fe}$ and $\mathrm{Mn}$ oxides increases significantly. The majority of the metal fraction associated with aluminosilicates remains in the composition of SB of $\mathrm{Cu}$ compounds, however its relative content decreases until $41 \%$ under anthropogenic load. Organic matter is actively involved in the retention of $\mathrm{Cu}$ both in strongly and weakly bound state.

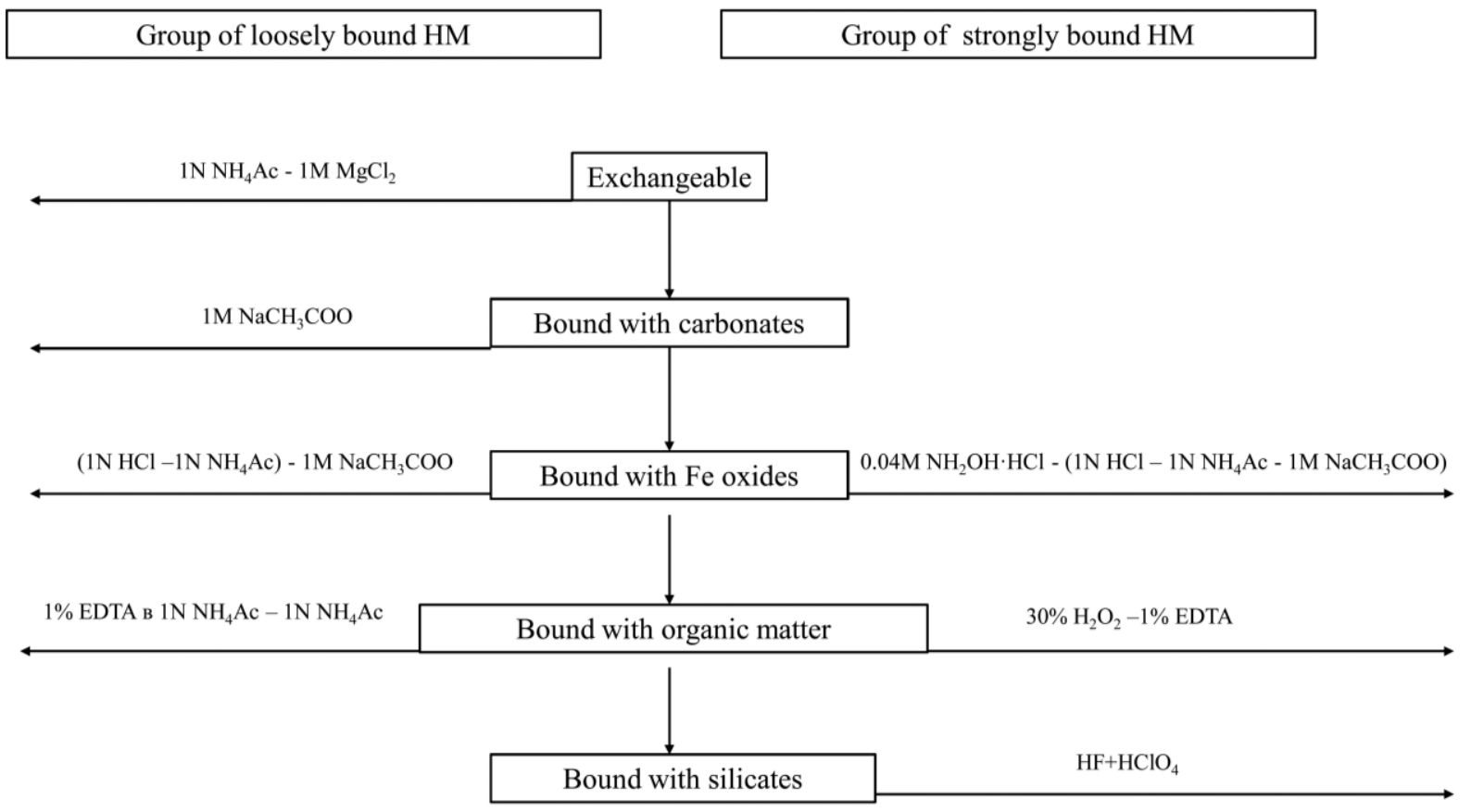

Figure 3. A combined fractionation scheme of HM-containing compounds in soil (Minkina et al., 2013).

The introduction of biochar caused changes in the ratio of the formed groups of metal compounds and their constituent fractions (Table 2). It has been shown that the sorbent has a significant effect on the transformation of $\mathrm{Cu}$ compounds in soil and introduction of sorbent decreased the metal mobility due to formation of SB compounds in all variants of the experiment.

Table 2. Distribution of $\mathrm{Cu}$ by forms and groups of compounds in the experimental meadow soil in the presence of biochar

\begin{tabular}{|c|c|c|c|c|c|c|c|c|c|}
\hline \multirow[t]{3}{*}{ Variant } & \multicolumn{4}{|c|}{ Loosely bound compounds } & \multicolumn{3}{|c|}{ trongly bound compounds with } & \multirow{3}{*}{$\begin{array}{l}\text { Sum of } \\
\text { fractions }\end{array}$} & \multirow{3}{*}{$\begin{array}{c}\mathrm{LB} / \mathrm{SB} \\
\% \text { of } \\
\text { sum }\end{array}$} \\
\hline & \multirow{2}{*}{ xchangeable } & \multirow{2}{*}{ complex } & \multicolumn{2}{|c|}{ specifically absorbed } & \multirow{2}{*}{$\begin{array}{r}\text { organic } \\
\text { matter }\end{array}$} & \multirow{2}{*}{$\begin{array}{r}\mathrm{Fe} \\
\text { oxide }\end{array}$} & \multirow[t]{2}{*}{ silicates } & & \\
\hline & & & $\begin{array}{r}\text { on } \\
\text { carbonates } \\
\end{array}$ & $\begin{array}{c}\text { on Fe ad Mn } \\
\text { oxide }\end{array}$ & & & & & \\
\hline \multirow[t]{2}{*}{ Control } & 0,2 & 0,8 & 1,6 & 0,7 & 8,3 & 3,2 & 28,9 & 43,7 & $8 / 92$ \\
\hline & 0,0 & 2,0 & 4,0 & 2,0 & 19,0 & 7,0 & 66,0 & & \\
\hline \multirow[t]{2}{*}{$\mathrm{Cu}$} & 27,1 & 216,4 & 81,2 & 189,3 & 175,8 & 108,3 & 554,5 & 1352,6 & $38 / 62$ \\
\hline & 2,0 & 16,0 & 6,0 & 14,0 & 13,0 & 8,0 & 41,0 & & \\
\hline \multirow[t]{2}{*}{$\mathrm{Cu}+1 \%$ biochar } & 13,6 & 122,4 & 68,1 & 108,8 & 271,9 & 136,1 & 639,3 & 1360,2 & $23 / 77$ \\
\hline & 1,0 & 9,0 & 5,0 & 8,0 & 20,0 & 10,0 & 47,0 & & \\
\hline \multirow[t]{2}{*}{$\mathrm{Cu}+2,5 \%$ biochar } & 9,4 & 67,4 & 53,9 & 57,6 & 350,9 & 121,3 & 687,4 & 1347,9 & $14 / 86$ \\
\hline & 1,0 & 5,0 & 4,0 & 4,0 & 26,0 & 9,0 & 51,0 & & \\
\hline
\end{tabular}

The relative content of LB metal compounds after use of biochar in dose $2.5 \%$ is almost equal to control variant with simultaneous redistribution of fractional-group composition of metal. In all fractions of LB cooper compounds, an increase of metal content both in absolute and relative concentrations was observed after introduction of carbonaceous sorbent into contaminated soils.

The higher metal content (up to $13 \%$ ) in fraction related with organic matter was noted. This trend can be related with the content of organic matter in soil which actively adsorbing $\mathrm{Cu}$ ions. Coal consists of one to two thirds of amorphous carbon, a part of which burn during activation forming pores of different diameter that results in extension of specific adsorbing surface as well as an increase of the content of organic matter in soil (O'Connor et al., 2018). The higher content of organic matter in soil due to addition of biochar can transform the instable $\mathrm{Cu}$ into the less mobile fractions, for example related with organic matter. Functional groups (such as $-\mathrm{OH},-\mathrm{COOH},-\mathrm{C}=\mathrm{O}-$ and $\mathrm{C}=\mathrm{N}$ ) on the biochar surface are also involved into interaction with metal forming the complexes and extending specific adsorption of metal. The content of residual fraction is also increasing that indicates the strong fixation of metal in soil in the presence of sorbent. 


\section{Conclusion}

Results showed the introduction of a highly porous carbonaceous sorbent (biochar) into the contaminated soil immobilized the mobile $\mathrm{Cu}$ compounds. An increase of a dose of sorbent in soil causes the more expressed changes of the content of loosely bound compounds with metal. The presented results showed possible remediation strategies using biochar for soil contaminated by $\mathrm{Cu}$.

\section{Acknowledgments}

This study was financially supported by the Russian Foundation for Basic Research, project no. 19-34-60041.

\section{References}

Ahmad, M., Rajapaksha, A.U., Lim, J.E., Zhang, M., Bolan, N., Mohan, D., Vithanage, M., Lee, S.S., Ok, Y.S., 2014. Biochar as a sorbent for contaminant management in soil and water: A review. Chemosphere 99: 19-33.

Ahmad, M., Usman, A.R.A., Al-Faraj, A.S., Ahmad, M., Sallam, A., Al-Wabel, M.I., 2018. Phosphorus-loaded biochar changes soil heavy metals availability and uptake potential of maize (Zea mays L.) plants. Chemosphere 194: $327-339$.

Burachevskaya, M., Minkina, T., Bauer, T., Mandzhieva, S., Gülser, C., Kızılkaya, R., Sushkova, S., Rajput, V., 2020. Assessment of extraction methods for studying the fractional composition of $\mathrm{Cu}$ and $\mathrm{Zn}$ in uncontaminated and contaminated soils. Eurasian Journal of Soil Science 9(3): 231-241.

Cao, X., Harris, W., 2010. Properties of dairy-manure-derived biochar pertinent to its potential use in remediation. Bioresource Technology 101(14): 5222-5228.

GN 2.1.7.2511-09, 2009. Approximate permissible concentrations of chemical substances in soil approved by the Chief State sanitary physician of the Russian Federation.

GOST (State Standard) 7657-84: Charcoal. Specifications. Moscow: Izd. Standartov, 1976. 7.

Houben, D., Evrard, L., Sonnet, P., 2013. Beneficial effects of biochar application to contaminated soils on the bioavailability of $\mathrm{Cd}, \mathrm{Pb}$ and $\mathrm{Zn}$ and the biomass production of rapeseed (Brassica napus L.). Biomass and Bioenergy 57: 196-204.

Huggins, T.M., Haeger, A., Biffinger, J.C., Ren, Z.J., 2016. Granular biochar compared with activated carbon for wastewater treatment and resource recovery. Water Research 94: 225-232.

Ju, W.L., Liu, L.Q., Fang, L.C., Cui, Y.X., Duan, C.J., Wu, H., 2019. Impact of co-inoculation with plant-growth-promoting rhizobacteria and rhizobium on the biochemical responses of alfalfa-soil system in copper contaminated soil. Ecotoxicology and Environmental Safety 167: 218-226.

Kabata-Pendias, A., 2011. Trace Elements in Soil and Plants. CRC Press, Boca Raton, USA. 548p.

Kars, N., Dengiz, O., 2020. Assessment of potential ecological risk index based on heavy metal elements for organic farming in micro catchments under humid ecological condition. Eurasian Journal of Soil Science 9(3): $194-201$.

Laird, D.A., Fleming, P., Davis, D.D., Horton, R., Wang, B., Karlen, D.L., 2010. Impact of biochar amendments on the quality of a typical Midwestern agricultural soil. Geoderma 158(3-4): 443-449.

Lamaming, J., Hashim, R., Sulaiman, O., Leh, C.P., Sugimoto, T., Nordin, N.A., 2015. Cellulose nanocrystals isolated from oil palm trunk. Carbohydrate Polymers 127: 202-208.

Li, S., Chen, G., 2018. Thermogravimetric, thermochemical, and infrared spectral characterization of feedstocks and biochar derived at different pyrolysis temperatures. Waste Management 78: 198-207.

Lomaglio, T., Hattab-Hambli, N., Miard, F., Lebrun, M., Nandillon, R., Trupiano, D., Scippa, G.S., Gauthier, A., MotelicaHeino, M., Bourgerie, S., Morabito, D., 2017. Cd, Pb, and Zn mobility and (bio)availability in contaminated soils from a former smelting site amended with biochar. Environmental Science and Pollution Research 25: 2574425756.

Minkina, T.M., Mandzhieva, S.S., Burachevskaya, M.V., Bauer, T.V., Sushkova, S.N., 2018. Method of determining loosely bound compounds of heavy metals in the soil. MethodsX 5:217-226.

Minkina, T.M., Motuzova, G.V., Mandzhieva, S.S., Nazarenko, O.G., Burachevskaya, M.V., Antonenko, E.M., 2013. Fractional and group composition of the $\mathrm{Mn}, \mathrm{Cr}, \mathrm{Ni}$, and $\mathrm{Cd}$ compounds in the soils of technogenic landscapes in the impact zone of the Novocherkassk Power Station. Eurasian Soil Science 46(4): 375-385.

O'Connor, D., Peng, T., Zhang, J., Tsang, D.S.W., Alessi, D.S., Shen, Z., Bolan, N.S., Hou, D., 2018. Biochar application for the remediation of heavy metal polluted land: A review of in situ field trials. Science of The Total Environment 619: 815-826.

Poucke, R.V., Ainsworth, J., Maeseele, M., Ok, Y.S., Meers, E., 2018. Tack Chemical stabilization of Cd-contaminated soil using biochar. Applied Geochemistry 88: 122-130.

Rees, F., Simonnot, M.O., Morel, J.L., 2014. Short-term effects of biochar on soil heavy metal mobility are controlled by intra-particle diffusion and soil pH increase. European Journal of Soil Science 65(1): 149-161.

Schloter, M., Nannipieri, P., Sorensen, S.J., Elsas, J.D.V., 2017. Microbial indicators for soil quality. Biology and Fertility of Soils 54: 1-10.

Shen, F., Liao, R., Ali, A., Mahar, A., Guo, D., Li, R., Sun, X., Awasthi, M.K., Wang, Q., Zhang, Z., 2017. Spatial distribution and risk assessment of heavy metals in soil near a $\mathrm{Pb} / \mathrm{Zn}$ smelter in Feng county, China. Ecotoxicology and Environmental Safety 139: 254-262. 
Tessier, A., Campbell, P.G.C., Bisson, M., 1979. Sequential extraction procedure for the speciation of particulate trace metals. Analytical Chemistry 51(7): 844-850.

Violante, A., Cozzolino, V., Perelomov, L., Caporale, A.G., Pigna, M., 2010. Mobility and bioavailability of heavy metals and metalloids in soil environments. Journal of Soil Science and Plant Nutrition 10: 268-292.

Wang, H-T., Ding, J., Chi, Q.-Q., Li, G., Pu, Q., Xiao, Z-F., Xue, X-M., 2020. The effect of biochar on soil-plant-earthwormbacteria system in metal(loid) contaminated soil. Environmental Pollution 263: 114610.

Wang, Y., Wang, R., Fan, L., Chen, T., Bai, Y., Yu, Q., Liu, Y., 2017. Assessment of multiple exposure to chemical elements and health risks among residents near Huodehong lead-zinc mining area in Yunnan, Southwest China. Chemosphere 174: 613-627.

Warnock, D.D., Lehmann, J., Kuyper, T.W., Rillig, M.C., 2007. Mycorrhizal responses to biochar in soil - concepts and mechanisms. Plant and Soil 300: 9-20.

Wood, J.L., Tang, C., Franks, A.E., 2016. Microbial associated plant growth and heavy metal accumulation to improve phytoextraction of contaminated soils. Soil Biology and Biochemistry 103: 131-137.

Zota, A.R., Willis, R., Jim, R., Norris, G.A., Shine, J.P., Duvall, R.M., Schaider, L.A., Spengler, J.D., 2009. Impact of mine waste on airborne respirable particulates in Northeastern Oklahoma, United States. Journal of the Air \& Waste Management Association 59(11): 1347-1357. 